\title{
Antecedents and consequences of bullying among nurses: a review study
}

\author{
Leila Alizadeh $^{1}{ }^{\circledR}$, Hedayat Jafari ${ }^{*}{ }^{(\mathbb{D}}$, Fereshteh Araghian Mojarad ${ }^{3}(\mathbb{D}$ \\ ${ }^{1}$ MSc Student in Emergency Nursing, School of Nursing and Midwifery, Nasibeh Sari, Mazandaran University of Medical \\ Sciences, Sari, Iran \\ ${ }^{2}$ Associate Professor, Traditional and Complementary Medicine Research Center, Addiction Institute, Mazandaran University of \\ Medical Sciences, Sari, Iran \\ ${ }^{3}$ Assistant Professor, Traditional and Complementary Medicine Research Center, Addiction Institute, Mazandaran University of \\ Medical Sciences, Sari, Iran
}

\begin{abstract}
Background and aims: Workplace bullying is an occupational hazard with destructive effects. The aim of this study was to assess the antecedents and the consequences of bullying among nurses.

Methods: This narrative review was conducted in 2021. An online literature search was performed in several Persian and English databases, namely Magiran, SID, Noormags, Elmnet, IranMedex, PubMed, and Scopus. Search protocol was limited to the time interval between 2010 and 2020. Search key terms were, "bullying", "coercion", "healthcare providers", "nurse", and "horizontal violence". Advanced search was also performed in Google Scholar. Inclusion criteria were publication in English or Persian, access to full-text, and publication as an original article.

Results: Sixteen articles were included in this study. The two main antecedents of workplace bullying were personal and organizational factors and the three main consequences of bullying were physical, mental, and occupational consequences.

Conclusion: As bullying is associated with different physical, mental, and occupational consequences, healthcare managers need to employ strategies to determine and manage bullying antecedents and reduce bullying prevalence.

Keywords: Bullying, Coercion, Nurse, Healthcare providers, Narrative review
\end{abstract}

\author{
*Corresponding Author: \\ Hedayat Jafari
}

Email: hjafari@mazums.ac.ir

Received: 7 February 2021 Accepted: 12 April 2021 ePublished: 30 June 2021

\section{Introduction}

Bullying at workplace is an occupational hazard (1) with potential risks and damages. By definition, bullying is any intentional, purposeful, regular, repeated, negative, and bothering behavior in bilateral relationships by one side against the other which is associated with overt or cover harms to the target person (2). Bullying includes a wide range of behaviors from passive behaviors such as negligence and intentional or purposeful ignorance to insulting behaviors associated with implied or explicit threat (2). The prevalence of workplace bullying in western countries was reported to be $5 \%-28 \%(3,4)$.

Bullying is highly prevalent among healthcare providers in hospitals, particularly nurses (5-7). A study on 260 nurses showed that more than $50 \%$ of them were the victims of bullying (8). Another study showed that bullying horizontally happened in hospitals and at least $34.9 \%$ of nurses experienced bullying each month (6). Another study found that bullying was 54\% more common among female nurses, $36 \%$ more common among younger nurses, and $24 \%$ less common among nurses with higher degrees (9).

Bullying at workplace can be associated with negative consequences such as disturbed inner peace, stress, and tension $(8,10)$. A meta-analysis reported that staff bullying at workplace can lead to problems such as turnover intention, reduced organizational commitment, low job satisfaction, absence from work, depression, anxiety, strain, tension, burnout, posttraumatic stress disorder, psychosomatic problems, and physical disorders (11).

Despite the serious outcomes of bullying among nurses, no review study had yet evaluated its different aspects. Therefore, the present study was performed to assess the antecedents and the consequences of bullying among nurses.

\section{Methods}

This narrative review was conducted in 2021. An online literature search was performed in several Persian and English databases, namely Magiran, SID, Noormags, Elmnet, IranMedex, PubMed, and Scopus. Search protocol was limited to the time interval between 2010 and 2020 . Search key terms were, "bullying", "coercion", "healthcare providers", "nurse", and "horizontal violence". Moreover, advanced search was performed in Google Scholar both in Persian and English. Inclusion criteria were publication in

(C) 2021 The Author(s); Published by Shahrekord University of Medical Sciences. This is an open-access article distributed under the terms of the Creative Commons Attribution License (http://creativecommons.org/licenses/by/4.0), which permits unrestricted use, distribution, and reproduction in any medium, provided the original work is properly cited. 
English or Persian, access to full-text, and publication as an original article. Duplicate records were omitted and the abstract of the remaining studies were reviewed. Then, a summary of the main findings of each study was prepared. As the methodologies of the included studies differed from each other, the narrative method was used for data summarization and categorization.

\section{Results}

Sixteen studies were included in this study. Fourteen studies were about bullying among nurses and four studies were about bullying among female nurses. Fourteen studies were into bullying among all nurses and four studies were into bullying among female nurses. Seven studies had been conducted in Iran and other studies had been conducted in the United States, South Korea, Poland, Taiwan, Italy, Saudi Arabia, and Jordan (Table 1). Most studies were descriptive.

Most participants in the reviewed studies had experienced bullying, particularly verbal bullying (Table 2). Bullying had significant negative relationship with hope, resilience, positive affect, and optimism. Moreover, it had significant positive relationship with gender, age, work experience, number of weekly work hours, organizational position, job-related negative affect, psychosomatic complaints, workplace incivility, emotional exhaustion, fatigue, physical complaints, humiliation, anger, malice, high occupational strain, and the depersonalization dimension of burnout.

The two main antecedents of workplace bullying were personal and organizational factors (Table 3 ) and the three main consequences of bullying were physical, mental, and occupational consequences (Table 4).

\section{Discussion}

This study assessed the antecedents and the consequences of bulling among nurses. Findings revealed that bullying had significant positive relationship with hope, resilience, positive affect, and optimism and significant negative relationship with job-related negative affect, emotional exhaustion, job burnout, and fatigue. Verbal bullying was the most prevalent type of bullying. Bullying had different effects on nurses.

Our findings showed that four studies were specific to bullying among female nurses $(12,13,20,23)$. Other studies

\begin{tabular}{ll} 
Table $\mathbf{1 .}$ Reviewed studies by country & N \\
\hline Country & 7 \\
\hline Iran & 2 \\
United States & 2 \\
South Korea & 1 \\
Poland & 1 \\
Taiwan & 1 \\
Italy & 1 \\
Saudi Arabia & 1 \\
Jordan &
\end{tabular}

had also reported the greater exposure of female nurses to bullying and its consequences. This finding may be due to women's physical conditions. Moreover, our findings revealed that bullying had significant positive relationship with job-related negative affect and psychosomatic complaints $(13,20,23)$ and significant negative relationship with hope, resilience, positive affect, and optimism $(13,19,20)$. These findings imply that the more the levels of hope, resilience, positive affect, and optimism are, the lower the levels of bullying complications will be. Moreover, we found that two of the reviewed studies had reported a negative relationship between bullying and age, implying that younger nurses experienced more bullying and more stress $(21,22)$, while a study had reported no significant relationship between age and perceived stress or anxiety (24). This contradiction may be due to the fact that those two studies had assessed the prevalence of bullying-related stress $(21,22)$, while the other study had assessed perceived bullying-related stress (24).

Some reviewed studies had reported the higher prevalence of verbal bullying (98.1\%) and the lower prevalence of non-verbal bullying (34\%) (21,25). Therefore, programs are needed to help nurses accurately assess workplace bullying (15). Educational programs about effective bullying management can also reduce concerns (21).

Our findings also showed that bullying had significant relationship with turnover intention $(7,14)$, emotional exhaustion, job burnout, and fatigue. Therefore, bullying prevention is essential to reduce job burnout and turnover among nurses (16). Moreover, we found that nurses with lower experience were more at risk for bullying and bullying was associated with a $61.7 \%$ decrease in productivity (17). However, a study showed no significant relationship between bullying and productivity (15). This contradiction highlights the necessity of further studies to

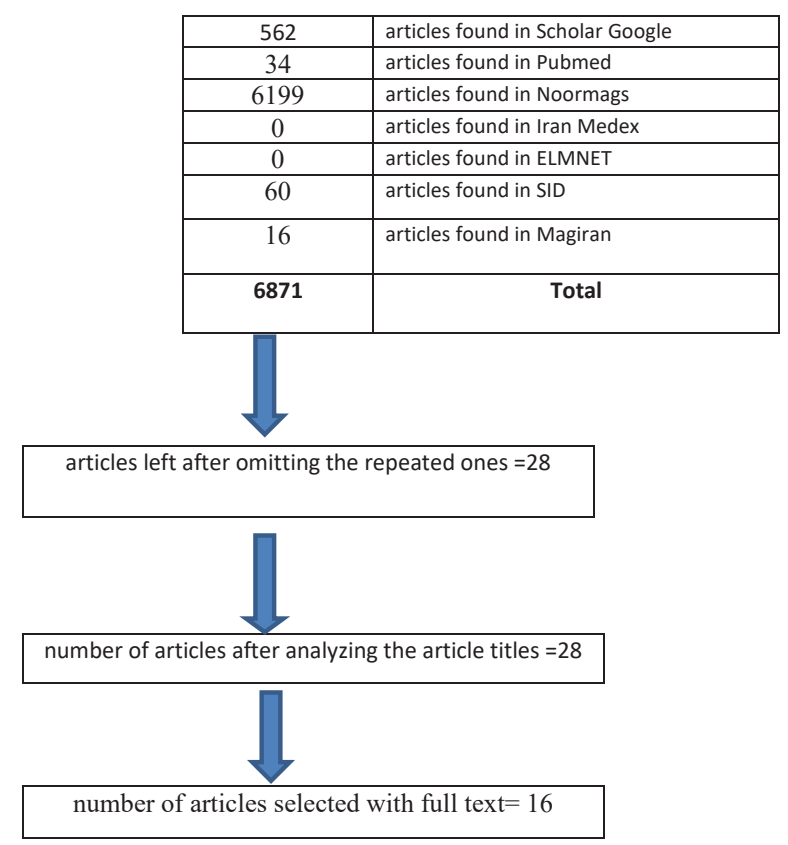

Figure 1. The process for searching, retrieving, and selecting the relevant articles 
Table 2. The characteristics of the reviewed studies

\begin{tabular}{|c|c|c|c|}
\hline Author & Title & Methods & Findings \\
\hline $\begin{array}{l}\text { Valian et al } \\
(12)\end{array}$ & $\begin{array}{l}\text { The effect of } \\
\text { organizational bullying } \\
\text { on individual sleep } \\
\text { according to the } \\
\text { mediating role of } \\
\text { rumination among female } \\
\text { nurses }\end{array}$ & $\begin{array}{l}\text { Population: Female nurses of Sayyad } \\
\text { Shirazi Hospital, Gorgan, Iran } \\
\text { Participants: } 144 \text { nurses selected } \\
\text { through simple random sampling } \\
\text { Instruments: Bullying Scale, } \\
\text { Questionnaire of Ruminative Thinking, } \\
\text { and Questionnaire of Sleep Quality. }\end{array}$ & $\begin{array}{l}\text { Organizational bullying had significant negative effects on sleep } \\
\text { duration. } \\
\text { Ruminative thinking moderated the effects of organizational bullying } \\
\text { on sleep quality. }\end{array}$ \\
\hline $\begin{array}{l}\text { Golparvar and } \\
\text { Khatonabadi } \\
\text { (13) }\end{array}$ & $\begin{array}{l}\text { Structural model } \\
\text { of the relationship } \\
\text { between bullying in } \\
\text { hospital environments } \\
\text { and negative affect } \\
\text { and psychosomatic } \\
\text { complaints among female } \\
\text { nurses }\end{array}$ & $\begin{array}{l}\text { Design: Correlational } \\
\text { Population: Female nurses of a } \\
\text { governmental hospital in Isfahan, Iran } \\
\text { Participants: } 243 \text { nurses selected } \\
\text { through convenience sampling } \\
\text { Instruments: Bullying Scale, Negative } \\
\text { Affect and Psychosomatic Complaints }\end{array}$ & $\begin{array}{l}\text { All six components of bullying had significant positive relationship } \\
\text { with negative affect and psychosomatic complaints. } \\
\text { Negative affect mediated the relationship between bullying and } \\
\text { psychosomatic complaints. }\end{array}$ \\
\hline $\begin{array}{l}\text { Salimi et al } \\
\text { (7) }\end{array}$ & $\begin{array}{l}\text { Investigation of bullying } \\
\text { and harassment in the } \\
\text { workplace using the } \\
\text { psychometric properties } \\
\text { of the Negative Acts } \\
\text { Questionnaire-revised } \\
\text { (NAQ-R) in nurses }\end{array}$ & $\begin{array}{l}\text { Design: Descriptive } \\
\text { Population: All nurses of Ayatollah } \\
\text { Rouhani Hospital, Babol, Iran } \\
\text { Participants: } 181 \text { nurses selected } \\
\text { through random sampling } \\
\text { Instruments: Negative Actions } \\
\text { Questionnaires-Revised (NAQ-R) and } \\
\text { Workplace Incivility Scale }\end{array}$ & $\begin{array}{l}\text { The } 22 \text {-item NAQ-R questionnaire had three factors, namely work- } \\
\text { related bullying, personal bullying, and turnover-related bullying. } \\
\text { Cronbach alpha coefficient of the NAQ-R questionnaire was } 0.94 \text {. } \\
\text { Cronbach alpha coefficients of NAQ-R dimensions were } 0.91,0.83 \text {, } \\
\text { and } 0.85 \text {, respectively. } \\
\text { The scores of all dimensions had significant positive correlation with } \\
\text { the score of the Workplace Incivility Scale. }\end{array}$ \\
\hline $\begin{array}{l}\text { Bambi et al } \\
\text { (14) }\end{array}$ & $\begin{array}{l}\text { Negative interactions } \\
\text { among nurses: an } \\
\text { explorative study on } \\
\text { lateral violence and } \\
\text { bullying in nursing work } \\
\text { settings }\end{array}$ & $\begin{array}{l}\text { Design: Web survey } \\
\text { Population: Nurses in three Tuscan } \\
\text { public health care institutions } \\
\text { Instruments: Negative Interactions } \\
\text { Among Nurses Questionnaire }\end{array}$ & $\begin{array}{l}\text { Response rate was } 18.6 \% \text {. } \\
\text { Around } 35.8 \% \text { of nurses reported negative interactions and } 42.3 \% \text { of } \\
\text { these nurses reported the experience of bullying. } \\
\text { Physical and psychological consequences of negative interactions } \\
\text { were reported by } 59 \% \text { of participants, and } 21.9 \% \text { of victims reported } \\
\text { thinking about leaving nursing. }\end{array}$ \\
\hline Ma et al (15) & $\begin{array}{l}\text { An app for detecting } \\
\text { bullying of nurses using } \\
\text { convolutional neural } \\
\text { networks and web-based } \\
\text { computerized adaptive } \\
\text { testing: development and } \\
\text { usability study }\end{array}$ & $\begin{array}{l}\text { Participants: } 960 \text { nurses working in a } \\
\text { hospital in Taiwan } \\
\text { Aim: Building a bully prediction model } \\
\text { to estimate } 69 \text { different parameters }\end{array}$ & $\begin{array}{l}\text { The } 22 \text {-item model for convolutional neural network was suggested } \\
\text { to improve the accuracy of assessment based on NAQ-R among } \\
\text { nurses and an app was developed for helping nurses assess bullying. }\end{array}$ \\
\hline Kim et al (16) & $\begin{array}{l}\text { Association between } \\
\text { workplace bullying and } \\
\text { burnout, professional } \\
\text { quality of life, and } \\
\text { turnover intention among } \\
\text { clinical nurses }\end{array}$ & $\begin{array}{l}\text { Design: Descriptive cross-sectional } \\
\text { Participants: } 324 \text { nurses } \\
\text { Instrument: A structured questionnaire }\end{array}$ & $\begin{array}{l}\text { Bullying had significant relationship with nurses' emotional } \\
\text { exhaustion, depersonalization dimension of burnout, and } \\
\text { compassion fatigue. Thus, bullying prevention was suggested to } \\
\text { reduce nurses' burnout and turnover. }\end{array}$ \\
\hline $\begin{array}{l}\text { Al-Ghabeesh } \\
\text { and Qattom } \\
(17)\end{array}$ & $\begin{array}{l}\text { Workplace bullying and } \\
\text { its preventive measures } \\
\text { and productivity among } \\
\text { emergency department } \\
\text { nurses }\end{array}$ & $\begin{array}{l}\text { Population: Emergency department } \\
\text { nurses in five hospitals in Amman, } \\
\text { Jordan } \\
\text { Participants: } 134 \text { nurses } \\
\text { Instruments: A demographic } \\
\text { questionnaire, Negative Acts } \\
\text { Questionnaire, Questions on } \\
\text { bullying Prevention, and a health and } \\
\text { productivity survey }\end{array}$ & $\begin{array}{l}\text { Ninety percent of participants reported bullying experience. Bullying } \\
\text { was associated with reduced ability to respond to cognitive needs, } \\
\text { establish effective communication, and provide safe care. The mean } \\
\text { score of bullying was } 94.51 \text { (in the possible range of } 42-168 \text { ). The } \\
\text { highest dimensional score was related to the personal dimension and } \\
\text { the highest item score was related to the item "Awareness of how to } \\
\text { report bullying". }\end{array}$ \\
\hline $\begin{array}{l}\text { Christie and } \\
\text { Jones (18) }\end{array}$ & $\begin{array}{l}\text { Lateral violence in } \\
\text { nursing and the theory of } \\
\text { the Nurse as Wounded } \\
\text { Healer }\end{array}$ & Presenting a theory & $\begin{array}{l}\text { Lateral violence, also known as horizontal violence, is a destructive } \\
\text { phenomenon at nurses' workplace. It may initially be explicit and } \\
\text { then, manifests implicitly. Its prevalence increases over time. The } \\
\text { cumulative effects of bullying may be severer than the effects of a } \\
\text { violent action. }\end{array}$ \\
\hline $\begin{array}{l}\text { Yoo and Ahn } \\
\text { (19) }\end{array}$ & $\begin{array}{l}\text { Nurses' workplace } \\
\text { bullying experiences, } \\
\text { responses, and ways of } \\
\text { coping }\end{array}$ & $\begin{array}{l}\text { Design: Descriptive } \\
\text { Participants: } 113 \text { hospital nurses }\end{array}$ & $\begin{array}{l}\text { Optimism reduced workplace bullying. Moreover, positive coping } \\
\text { strategies were associated with lower bullying responses. }\end{array}$ \\
\hline $\begin{array}{l}\text { Golparvar et } \\
\text { al (20) }\end{array}$ & $\begin{array}{l}\text { The study of the } \\
\text { correlation between } \\
\text { bullying at workplaces } \\
\text { and psychosomatic } \\
\text { complaint and affective } \\
\text { wellbeing among female } \\
\text { nurses }\end{array}$ & $\begin{array}{l}\text { Design: Descriptive-correlational } \\
\text { Population: Female nurses working in } \\
\text { hospitals in Yazd, Iran } \\
\text { Participants: } 252 \text { nurses selected } \\
\text { through convenience sampling } \\
\text { Instrument: Bullying questionnaire, } \\
\text { Physical Complaints Questionnaire, } \\
\text { and Occupational Emotions }\end{array}$ & $\begin{array}{l}\text { Workplace bullying had significant relationship with physical } \\
\text { complains, work-related negative affect, humiliation, anger, malice, } \\
\text { and occupational strain. Moreover, occupational strain was a } \\
\text { significant predictor of work-related negative affect. }\end{array}$ \\
\hline
\end{tabular}


Table 2. Continued

\begin{tabular}{|c|c|c|c|}
\hline Author & Title & Methods & Findings \\
\hline $\begin{array}{l}\text { Al-Surimi et } \\
\text { al (9) }\end{array}$ & $\begin{array}{l}\text { Prevalence of workplace } \\
\text { bullying and its } \\
\text { associated factors at a } \\
\text { multi-regional Saudi } \\
\text { Arabian hospital: a cross- } \\
\text { sectional study }\end{array}$ & $\begin{array}{l}\text { Design: Cross-sectional } \\
\text { Participants: All fulltime healthcare } \\
\text { practitioners in a multi-regional } \\
\text { hospital in Saudi Arabia } \\
\text { Instrument: A self-administered } \\
\text { questionnaire distributed via a private } \\
\text { electronic mail }\end{array}$ & $\begin{array}{l}\text { Most participants reported workplace bullying ( } \mathrm{n}=684) \text {. Bullying } \\
\text { agents were patients }(36.1 \%) \text {, patients' family members }(29.5 \%) \text {, } \\
\text { hospital staff }(27.2 \%) \text {, and managers }(7.2 \%) \text {. The most common types } \\
\text { of bullying were verbal abuse }(98.1 \%) \text {, physical assault }(11.8 \%) \text {, } \\
\text { and sexual connotations }(5.8 \%) \text {. While } 63.7 \% \text { of participants had } \\
\text { experienced workplace bullying, only } 11 \% \text { of them had received } \\
\text { education about workplace bullying. Physicians with higher degrees } \\
\text { and lower experience were more worried about the negative effects } \\
\text { of workplace bullying on care quality and patient safety. Previous } \\
\text { experience of bullying was associated with higher worry, while } \\
\text { education about bullying management was associated with lower } \\
\text { worry. }\end{array}$ \\
\hline
\end{tabular}

nursing workplace and Participants: 404 nurses with a work

its determinant factors: experience of more than six month Instruments: Polish version of the a nationwide cross-

(21) sectional Polish study Negative Act Questionnaire-Revised.

Experience of bullying was reported by $65.84 \%$ of participants. Perceived workplace bullying had significant relationship with age, gender, work experience, number of work hours, and organizational position. survey

Design: Descriptive-correlational

bullying in hospital and governmental hospital in Isfahan, Iran

Khatonabadi the psychotic complaints (22) of female nurses by considering the role of resilience and hope

Bullying in workplace Mollabahrami (23) and its impact on commitment

Participants: 243 nurses selected through convenience sampling Instruments: Questionnaire of Resilience and Hope, Bullying, and Psychosomatic Complaints

Participants: 134 nurses The relationship between Population: Female nurses in a

Golparvar and bullying in

Shahbazi and nurses' occupational

All six components of bullying had significant positive relationship with psychosomatic complaints and significant negative relationship with hope and resilience. Hope and resilience moderated the relationship of insult and humiliation with psychosomatic complaints. In other words, insult and humiliation had no significant relationship with psychosomatic complaints when hope and resilience were high and vice versa.

Workplace bullying had significant negative relationship with nurses' organizational commitment and its three dimensions.

Most participants reported the experience of workplace bullying $(59.5 \%)$ and $32 \%$ of them reported exposure to frequent daily bullying. Those who were exposed to bullying reported higher perceived stress and anxiety. Perceived stress and anxiety had no significant relationship with age, while posttraumatic stress Design: Mixed method (quantitativequalitative)

Psychological distress Population: Nurses in three Midwestern states

Berry et al and workplace bullying among registered nurses

Instruments: Web-based survey in the quantitative phase and semi-structured interviews in the qualitative phase cient, perceived stress, anxiety, and posttraumatic stress disorder had no significant relationship with work experience, gender, bullying outside work, academic progress, race, and social support. Content analysis of interview data revealed four main categories, namely construct of bullying, permissive culture of bullying, the toxic effects of bullying, and fostering a positive work culture.

Sixty nine percent of nurses had never experienced bullying, $9 \%$ frequently experienced bullying, and $22 \%$ had previously experienced bullying. Verbal bullying was the most common type of bullying and $40 \%$ of nurses reported the experience of verbal

Participants: 162 nurses from four Nasr-Esfahani Workplace bullying and Shahbazi in nursing: Azerbaijan (25) hospitals in West Azerbaijan Province, Iran bullying. Moreover, $83 \%$ of nurses reported no experience of practical bullying, 22\% reported occasional experience of practical bullying, and $9 \%$ of them reported frequent experience of practical bullying. The prevalence of non-verbal and functional bullying was $34 \%$ and $31 \%$, respectively.
Table 3. Antecedents of workplace bullying

\begin{tabular}{ll}
\hline Antecedents & Age, gender, education, marital status, work experience, \\
personal & $\begin{array}{l}\text { poceiving work hours, overtime work, service duration, } \\
\text { bullying and accepting nursing conditions }\end{array}$ \\
& $\begin{array}{l}\text { Organizational weaknesses, lack of education on how } \\
\text { to cope with bullying, organizational support for nurses, } \\
\text { proper interaction in organization, and safety culture in } \\
\text { Organization }\end{array}$ \\
\hline
\end{tabular}

determine the consequences of bullying.

Our findings also indicated that bullying had significant negative relationship with occupational commitment (23). Bullying is a destructive phenomenon at workplace
Table 4. Consequences of workplace bullying

\begin{tabular}{ll}
\hline Consequences & \\
\hline \multirow{3}{*}{ Physical } & $\begin{array}{l}\text { Physical complaints, tachycardia, headache, fatigue, } \\
\text { change in blood pressure, reduced sleep quality, } \\
\text { reduced sleep duration, excessive cigarette smoking, } \\
\text { excessive alcohol use, overeating, reduced interpersonal } \\
\text { interactions, premature death }\end{array}$ \\
& $\begin{array}{l}\text { Emotional exhaustion and depersonalization, anger } \\
\text { and malice, psychosomatic complaints, reduced ability } \\
\text { Psychological } \\
\text { to respond to cognitive needs, environmental stress, } \\
\text { negative interactions, posttraumatic stress disorder, } \\
\text { suicide, domestic violence, depression and anxiety, } \\
\text { emotional-psychological problems }\end{array}$ \\
& $\begin{array}{l}\text { Turnover intention, disinterest in job, job burnout, } \\
\text { negative changes in functioning, reduced productivity, } \\
\text { Occupational } \\
\text { omission of benefits, reduced care quality and patient } \\
\text { safety }\end{array}$ \\
\hline
\end{tabular}


What does this paper contribute to the wider global clinical community?

- Workplace bullying is highly prevalent among nurses.

- Different personal and organizational factors contribute to workplace bullying among nurses.

- Workplace bullying among nurses is associated with different physical, mental, and occupational consequences.

- Close supervision and management of nurses' interpersonal conflicts and quality education about effective conflict management for them are recommended for effective bullying prevention.

which may seem primarily harmless, while its negative cumulative effects can be severer than the effects of a violent action (18).

\section{Conclusion}

This study shows the prevalence of workplace bullying among nurses due to personal and organizational factors and with different physical, mental, and occupational consequences. Nursing managers need to improve their supervision of nurses' interpersonal conflicts and provide them with education about effective conflict management and bullying prevention. All healthcare managers and providers, particularly nurses, need to have close collaboration with each other in order to create a safe workplace. Further studies are needed to explore the antecedents of bullying and the most effective strategies for its prevention.

\section{Acknowledgement}

We would like to thank the staff of the library of Nasibeh, Faculty of Nursing and Midwifery, Sari, Iran, as well as the instructors of this faculty who helped us conduct this study.

\section{Conflict of interests}

None is declared.

\section{Ethical Approval}

Not applicable.

\section{References}

1. Muslimi M, Koushki Jahromi A, Mansouri M. Bullying at Work, National Conference on Development Management 2016. (Challenges and Solutions in Public and Private Organizations), Bandar Abbas. https://civilica.com/doc/679610. [Persian].

2. Golparvar M, Sadeghi S, Mosahebi M. Construction and Validation of Bulling at Workplace Questionnaire. Isfahan (Khorasgan) Branch: Islamic Azad University; 2012. [Persian].

3. Trépanier SG, Fernet C, Austin S. A longitudinal investigation of workplace bullying, basic need satisfaction, and employee functioning. J Occup Health Psychol. 2015;20(1):105-16. doi: 10.1037/a0037726.

4. Lutgen-Sandvik P, Tracy SJ, Alberts JK. Burned by bullying in the American workplace: prevalence, perception, degree and impact. J Manag Stud. 2007;44(6):837-62. doi: 10.1111/j.1467-6486.2007.00715.x.

5. Imani B, Nazari L, Majidi L, Zandieh M, Tajobi M. Investigation of the causes and solutions to violence in the workplace, emergency nurses in selected hospitals of Hamadan University of Medical Sciences. Pajouhan Scientific Journal. 2014;12(2):64-74. [Persian].

6. Heidari Gorji MA, Jannati Y, Yazdani Cherati J, Jafari K. Horizontal violent behavior in critical care nurses and related factors. J Mazandaran Univ Med Sci. 2015;25(123):78-86. [Persian].

7. Salimi H, Mehralitabr Firozjaie A, Najarpourian S, Ziaaddini Z. Investigation of bullying and harassment in the workplace using the psychometric properties of the negative acts questionnaire-revised (NAQ-R) in nurses. Qom Univ Med Sci J. 2019;12(11):60-9. doi: 10.29252/qums.12.11.7. [Persian].

8. Ovayolu O, Ovayolu N, Karadag G. Workplace bullying in nursing. Workplace Health Saf. 2014;62(9):370-4. doi: 10.3928/21650799-20140804-04.

9. Al-Surimi K, Al Omar M, Alahmary K, Salam M. Prevalence of workplace bullying and its associated factors at a multiregional Saudi Arabian hospital: a cross-sectional study. Risk Manag Healthc Policy. 2020;13:1905-14. doi: 10.2147/rmhp. s265127.

10. Akar N. The relationships among perceived job stressors, workplace bullying and job stress in the health care services in Turkey: a structural equation modeling (SEM) approach. Int J Humanit Soc Sci. 2013;3(14):248-57.

11. Nielsen $M B$, Einarsen $S$. Outcomes of exposure to workplace bullying: a meta-analytic review. Work Stress. 2012;26(4):30932. doi: 10.1080/02678373.2012.734709.

12. Valian H, Koushki Jahromi A, Niloufari P. The effect of organizational bullying with individual sleep quality with respect to a mediating role rumination among hospital female nurse. Journal of Counseling Research. 2017;16(64):127-53. [Persian].

13. Golparvar M, Khatonabadi G. Structural model of the relationship between bullying in hospital environments and negative effect and psychosomatic complaints among female nurses. Iranian Journal of Psychiatric Nursing. 2017;4(5):52-9. doi: 10.21859/ijpn-04058. [Persian].

14. Bambi S, Guazzini A, Piredda M, Lucchini A, De Marinis MG, Rasero L. Negative interactions among nurses: an explorative study on lateral violence and bullying in nursing work settings. J Nurs Manag. 2019;27(4):749-57. doi: 10.1111/jonm.12738.

15. Ma SC, Chou W, Chien TW, Chow JC, Yeh YT, Chou PH, et al. An app for detecting bullying of nurses using convolutional neural networks and web-based computerized adaptive testing: development and usability study. JMIR Mhealth Uhealth. 2020;8(5):e16747. doi: 10.2196/16747.

16. Kim Y, Lee E, Lee $\mathrm{H}$. Association between workplace bullying and burnout, professional quality of life, and turnover intention among clinical nurses. PLoS One. 2019;14(12):e0226506. doi: 10.1371/journal.pone.0226506.

17. Al-Ghabeesh SH, Qattom H. Workplace bullying and its preventive measures and productivity among emergency department nurses. BMC Health Serv Res. 2019;19(1):445. doi: 10.1186/s12913-019-4268-x.

18. Christie $\mathrm{W}$, Jones $\mathrm{S}$. Lateral violence in nursing and the theory of the nurse as wounded healer. Online J Issues Nurs. 2013;19(1):5. doi: 10.3912/OJIN.Vol19No01PPT01.

19. Yoo SY, Ahn HY. Nurses' workplace bullying experiences, responses, and ways of coping. Int J Environ Res Public Health. 2020;17(19):7052. doi: 10.3390/ijerph17197052.

20. Golparvar M, Rafizadeh H, Arefi M. The study of the correlation between bullying at workplaces and psychosomatic complaint and affective wellbeing among women nurses. Pajoohandeh Journal. 2015;19(6):328-34. [Persian].

21. Serafin LI, Czarkowska-Pączek B. Prevalence of bullying 
in the nursing workplace and determinant factors: a nationwide cross-sectional Polish study survey. BMJ Open. 2019;9(12):e033819. doi: 10.1136/bmjopen-2019-033819.

22. Golparvar M, Khatonabadi G. The relationship between bullying in hospital and the psychotic complaints of female nurses by considering the role of resilience and hope. Health Research Journal. 2018;3(4):254-62. doi: 10.29252/ hrjbaq.3.4.254. [Persian].

23. Shahbazi G, Mollabahrami H. Bullying in the workplace and its impact on nurses' job commitment, Fourth National
Conference on Management, Accounting and Economics with emphasis on regional and global marketing, Tehran, 2018. https://civilica.com/doc/915261. [Persian].

24. Berry PA, Gillespie GL, Fisher BS, Gormley D, Haynes JT. Psychological distress and workplace bullying among registered nurses. Online J Issues Nurs. 2016;21(3):8. doi: 10.3912/OJIN.Vol21No03PPT41.

25. Nasr Esfahani A, Shahbazi G. Workplace bullying in nursing: the case of Azerbaijan province, Iran. Iran J Nurs Midwifery Res. 2014;19(4):409-15.

Cite this article as: Alizadeh L, Jafari H, Araghian Mojarad F. Antecedents and consequences of bullying among nurses: a review study. Journal of Multidisciplinary Care.2021;10(2):87-92.doi:10.34172/jmdc.2021.17. 